\title{
The Flipped Classroom for Teaching Millennials: A Competency-Based Pedagogical Approach
}

\author{
Josephine Chinying Lang \\ Nanyang Business School, Nanyang Technological University, Singapore \\ Email: acylang@ntu.edu.sg
}

How to cite this paper: Lang, J. C. (2017). The Flipped Classroom for Teaching Millennials: A Competency-Based Pedagogical Approach. Creative Education, 8, 1571-1589. https://doi.org/10.4236/ce.2017.810108

Received: June 29, 2017

Accepted: August 5, 2017

Published: August 8, 2017

Copyright $\odot 2017$ by author and Scientific Research Publishing Inc. This work is licensed under the Creative Commons Attribution International License (CC BY 4.0).

http://creativecommons.org/licenses/by/4.0/

\begin{abstract}
This paper describes a competency-based pedagogical framework as the basis for designing a flipped classroom for millennials taking an undergraduate course on sustainable business. Its theoretical underpinnings are culled from the literatures on learner empowerment, epistemological belief systems, and the social construction of knowledge. The desired learning outcomes of this pedagogical framework include the development of cognitive competencies, collaborative knowledge acquisition skills, and motivational skills. In a flipped classroom of an undergraduate sustainability course, students acquired these competencies and skills to use intelligently information about sustainability which they found on the Internet. The paper describes in some detail how the course was taught in an actual class to impart such competencies and skills. The flipped-classroom pedagogy allows for better student learning outcomes by incorporating student collaboration, and by fostering critical thinking and ethical reasoning. The paper demonstrates how teacher and student benefit from the competency-based pedagogical approach within a flipped-classroom format. This approach moves beyond the traditional giver and receiver format to a more fellow-explorer format.
\end{abstract}

\section{Keywords}

Pedagogy, Sustainability, Knowledge Epistemology, Social Construction of Reality, Flipped Classroom, Millennials

\section{Introduction}

Integrating sustainability in management and business education has been a topic of interest for some time now. For instance, as far back as June 2009, the Journal of Management Education devoted a special issue to the "Greening and 
Sustainability across the Management Curriculum" (Rusinko \& Sama, 2009). The issue of sustainability is both interdisciplinary and multidisciplinary. Sustainability issues are real and have practical implications for how societies selforganize and how people live. Therefore, it is important that innovative teaching pedagogies be adopted to facilitate the learning of how business can be sustainable.

The objective is for students to come to truly understand the concept of sustainability, embody it, and then, if possible at all, practice its principles the rest of their lives. To get them there, the teaching pedagogy must foster those cognitive competencies and collaborative skills which they will need to be able to critically analyse the information that they might gather from diverse sources. The point of such critical analyses is to eventually generate a coherent and logical understanding of sustainability.

This is all the more urgent given that the millennial's world is a wired one, where information is available on demand and on the go. Specifically, the millennial's world is one of the social media, where $24 / 7$ social connectedness is normative. To make sense of the deluge of information on sustainability, in this case, it is no longer sufficient for the millennial to just comprehend the written word or videos on the Internet. Instead, she must be able to process all that information to assess it for truth, relevance and validity. Current pedagogical practices do not promote these desiderata. Instead, they still tend to emphasize the acquisition of knowledge, such as environmental facts, scientific evidence, or management concerns.

This article outlines a different approach taken by the author in teaching an undergraduate sustainability course in the business school of a particular university in Singapore. The approach uses a competency-based pedagogical framework so that students can develop a holistic view of sustainability using different theoretical and stakeholder perspectives and yet also remain mindful of implicit and unexamined assumptions and contextual influences, if any.

By way of genuine conversations in teams, and in specially created online knowledge communities, students began to integrate knowledge shared by other team members and to collaboratively develop shared understandings of various sustainability issues in business. Such active engagement in the face-to-face classroom and in online knowledge communities made sustainability issues come alive. This dispelled the notion that learning was largely about acquiring substantive content the professor might deliver. Instead this competency-based approach presented learning as an active process, in the context of an effective course design through a thoughtful synthesis of content, technology and educational pedagogy. By emphasizing the development of a set of cognitive competencies and interpersonal skills, students were motivated to actively engage their minds when dealing with the course material. Such mindfulness was a necessary first step to stimulating a genuine interest in sustainability and empowering the learner.

This paper begins by presenting the competency-based approach that was 
adopted in an undergraduate course on environmental sustainability in a multi-discipline university. The course design incorporated the development of several cognitive competencies and collaborative skills. Specifically, these cognitive competencies included critical thinking, and ethical reasoning; while the collaborative skills included collaborative knowledge acquisition and skills in motivating oneself and motivating others. Once all this is set out, the theoretical justifications for this approach are then discussed, which include learner empowerment, the epistemological beliefs of learners, and the social construction of knowledge. Finally, the paper presents some evidence for successful learning utilizing this approach in the course concerned.

\section{The Competency-Based Approach in an Undergraduate Course on Sustainable Business}

This paper describes an undergraduate sustainability course in a business school, where the author adopted a competency-based approach (Figure 1) from the time it was introduced in 2012. This approach focused on helping students to develop, first, the cognitive competencies needed for self-regulated learning; and, secondly, the interpersonal skills needed for knowledge-sharing in collaborative learning. This approach also attempted to transform students from the reflexive mindset where an answer to a sustainability issue was either right or wrong to one where there was more of an individual understanding based on the social construction of meaning.

True learning is never straightforward. Since experts, researchers and scientists, may hold opposite viewpoints on a particular issue in dispute, there may not always exist already a consensus or received view on the matter. In such contexts, the educator's main concern ought not to be whether her students ultimately acquire apodictic content or knowledge. She should ask instead: "Did they grapple with the information in the process of acquiring it? Did they hold on to some preconceived notion? Or, did they try to construct new meanings based on emerging contextual facts or figures?"

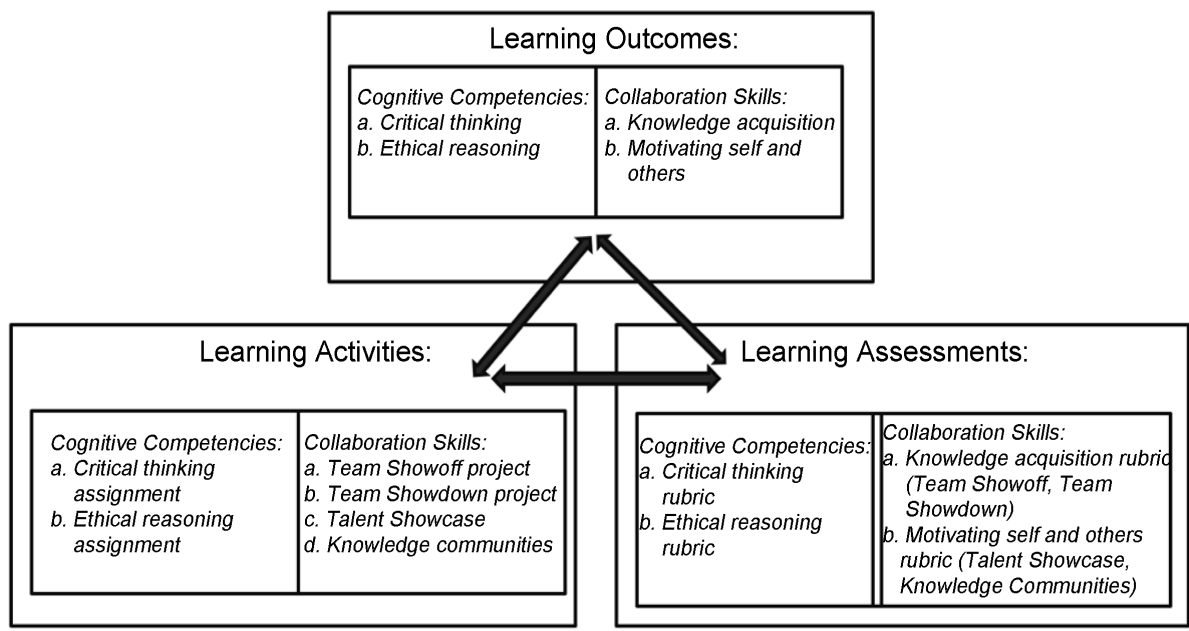

Figure 1. The competency-based pedagogical model. 
This competency approach seeks to liberate the student from a blind acquiescence in and acceptance of received wisdom; and, to encourage her, instead, to critically examine the relevance and validity of information encountered. The upshot is to impel the student into embracing an authentic learning mindset. To get to this point, however, the educator herself must first take a step back, critically re-examine, and re-configure her classes to create conditions for self-regulated and collaborative learning.

Figure 1 depicts the three important components of the competency-based pedagogical model to create the conditions for self-regulated and collaborative learning. These components are: learning outcomes, learning activities, and learning assessments.

\subsection{Learning Outcomes}

This pedagogical design adopts a learner-centered, outcomes-based approach. Driscoll and Wood (2007) described this as one that makes learning outcomes transparent to learners by setting forth clear expectations of how performance is to be assessed. The learning outcomes desired are those cognitive competencies and collaborative skills that students should acquire as a result of their learning (Ewell, 2001). Regardless of the mode of teaching, whether face-to-face, or online, or blended, it is important to identify the expected learning outcomes. This is because identifying the expected outcomes will guide, first, the design of not just the curricular content but also the learning activities for the course; and, secondly, the decision as to what assessment methods might be appropriate.

For the approach presented in Figure 1 for the class mentioned, two sets of cognitive competencies were emphasized, namely, critical thinking, and ethical reasoning. In addition, two sets of collaborative skills were stressed, namely, collaborative knowledge acquisition, and motivational skills.

\subsection{Learning Activities}

In this approach, the learning activities for the course mentioned were specially designed to facilitate the acquisition of the aforementioned cognitive competencies, and collaborative skills. For the former, two sets of skills were emphasized, viz., critical thinking, and ethical reasoning. For the latter, two other sets of skills were stressed, viz., collaborative knowledge acquisition, and motivational skills. These are considered in turn below.

First, to facilitate critical thinking, students were required to write a critique of an assigned news report about an environmental issue. For example, the following news reports were chosen for students to critique:

1) Lee, Jia Xin (2012), "Supermarts may start charging for plastic bags", The Straits Times, Apr. 23.

2) Vaughan, Victoria (2010). "Is Singapore the worse environmental offender?” The Straits Times, May 14, 2010.

3) Hance, Jeremy (2013) "Eat insects to mitigate deforestation and climate change”, mongaby.com, May 14. 
4) Chang, Kenneth, (2012) "Stanford scientists cast doubt on advantages of organic meat and produce", The New York Times, Sept. 3.

In writing a critique of an assigned news report, students were advised to use the criteria in a critical thinking rubric they were provided with to guide them through the thinking process. They were encouraged to do a comprehensive search for additional information on their own and then be critical in their analyses about the issues discussed in a given news report. The information search was to be from a variety of sources, including also peer-reviewed articles from academic journals of different disciplines.

Through a self-initiated search process, students explored on their own the various viewpoints and theoretical perspectives that different experts may have adopted. In this way, the students (became aware that they) did not acquire knowledge in a linear manner from the chalk-and-talk teacher seen (putatively) as sage-on-stage. Instead, (they became aware that) they had acquired knowledge through a process of examining alternative explanations. They had to weigh the strengths and weaknesses of various arguments, along with the evidence in support of an argument. Moreover, they had to consciously attempt to reconcile differing viewpoints in order that a working understanding of the matter can be synthesized at the end of the process.

Secondly, to facilitate ethical reasoning, students were required to analyze an ethical dilemma using different ethical reasoning approaches to deal with the complexities inherent in the dilemma. For the course mentioned, the following news reports were assigned to the students for this purpose:

1) Levick, Richard (2012). "Big Google is Watching You", Forbes, May 3.

2) Quinn, Ben (2012). "Ikea apologises over removal of women from Saudi Arabia catalogue", The Guardian, October 2.

3) Mielach, David (2012). "Is it ethical to own an iPhone?" Business News Daily, Feb. 2.

4) Birrell, Ian, (2010). "Before you pay to venture abroad, think of the harm you might do", The Guardian, Nov. 14.

In writing their ethical analyses of an environmental dilemma, students were encouraged to use the criteria provided in an ethical reasoning rubric to guide them through the ethical reasoning process. As they systematically examined a given dilemma from different ethical perspectives (such as ethical egoism, utilitarianism, deontology, etc.), it would dawn on them that different perspectives pointed to differing ways of looking at the ethics of the dilemma.

As always, that information is often incomplete was something that would become quite evident to students in trying to make sense of such a dilemma. To overcome the problem of incomplete information, students were encouraged to read far and wide, beyond the news report. They were to search for more information on the Internet, including material that might only be found in academic databases, for example.

In having to grapple with the uncertainties inherent in each dilemma, students were compelled to surface the ambiguities embedded in a given news report and 
become alerted to how such ambiguities might impact their understanding of the dilemma in question. In this manner, students came to grasp how dilemmas were not generally black or white but shot through, rather, with uncertainties and ambiguities, given incomplete information. Under such circumstances, they would find themselves having consciously attempt to reconcile contradictory viewpoints before taking a stand on the dilemma-not perhaps a final stand, as such, but more of a modus vivendi, perhaps.

Thirdly, to facilitate collaborative knowledge acquisition, it must be noted that knowledge acquisition itself is not just cognitive and personal in nature. Instead, acquiring knowledge also involves the process of social interactions. That is, to learn well, students must learn not just on their own but also collaboratively. Regarding the latter, students must learn to share their knowledge with one another in what should be seen as mutual teaching and mutual learning. Students reap richer learning experiences from their active engagement with fellow learners while developing the essential cognitive competencies and team skills to make their learning effectiveness.

In the course mentioned, the following was done to promote knowledge acquisition within a social context. Two team projects, which the author called "Team Showdown", and "Team Showoff", were designed to motivate students to acquire knowledge within the social context of their teams. Students were expected to apply the five criteria found in the knowledge acquisition rubric they were provided with to complete both team assignments.

For the Team Showdown project, students working in teams of five or six (i.e., the Showdown Team) perused the course material (consisting of PowerPoints and content from an e-book written by the author for the course) for a particular class ("seminar"). They were to generate a total of five questions according to the five criteria. By getting students to develop the questions themselves, they came to acquire a sense of ownership of those questions they asked and were thus more motivated to find the answers on their own.

Each Showdown Team was required to provide answers to the questions it had generated. For the seminar assigned, the Showdown Team concerned would distribute the five questions to other teams in class to answer. The Showdown Team members would then provide the necessary guidance should the other teams encounter problems in answering the questions assigned.

For the Team Showoff project, each team analyzed the sustainability efforts of two companies in a systematic fashion, by applying the five criteria of knowledge acquisition given in a rubric. The team concerned was to apply relevant concepts and frameworks to organize the information it gathered to compare how sustainable the various practices of the two companies were. During planning meetings, students would go through the relevant course PowerPoints and e-book content and also do their own research on the Internet to see what concepts and frameworks were relevant in comparing their pair of companies.

By using two team projects to emphasize knowledge acquisition, students were given two different opportunities to acquire not just content knowledge but 
also to internalize the process of acquiring knowledge through a social process of knowledge construction.

Finally, two things were done to promote the student's motivational skills. On the one hand, to encourage self-motivation in the course mentioned, students were pre-assigned as the "Talent of the Day" to discuss a specific sustainability case in class. To set this activity apart from the usual class participation, this in-class activity was named "Talent Showcase". Working individually, the student concerned would gather information related to the environmental strategies of a specific business organization and how it implemented those strategies. In class, the student's task was to share her knowledge of the case with all present.

On the other hand, to get students to want also to motivate others to learn, they were required to participate in online knowledge communities. These were online discussion forums specially designed to run for exactly 24 hours from immediately after the end of each class. In these knowledge communities, students were free to deliberate on any issues related to the topics covered in that particular class.

In such conversations in these knowledge communities, students had ample opportunities to explore in greater depth those issues that were of interest to them; voice their disagreements to viewpoints expressed in class; and, generate interesting questions for others to think about. For example, after a class on sustainable production practices, one student posed a question on the forum as to whether cloth made from bamboo was more sustainable than cotton. Other students, motivated by the curiosity generated, began to find out more about the production of fiber from bamboo, which was not something that most people might be aware of. In yet another class on green innovations, another student posed a question about the possible impact of nanotechnologies on future innovations. This triggered off searches about nanotechnologies, which led to a lively discussion about the how nanotechnologies might be deployed to ameliorate the potentially negative environmental impacts of such innovations instead.

\subsection{Learning Assessments}

To assess the cognitive competencies and collaborative skills of students, rubrics that clearly state the criteria for such evaluation are needed. Students use these rubrics as guides in doing their assignments. The instructor must, in turn, give them feedback on how well they perform on each criterion that is listed in the rubric concerned.

For critical thinking, students in the course mentioned were assessed on five criteria that have been identified as the main components of critical thinking (Alghalith, 2015). The five criteria listed in the critical thinking rubric were:

1) Identifies and summarizes the issue at hand;

2) Identifies and considers other theoretical perspectives that are important to the analysis of the issue;

3) Identifies and assesses the quality of supporting data/evidence and provides 
additional data/evidence related to the issue;

4) Identifies and considers key assumptions and the influence of the context on the issue;

5) Identifies and assesses conclusions, implications and consequences.

For ethical reasoning, students were assessed on the five criteria that were listed in the ethical reasoning rubric:

1) Issue definition: Defines the issue of the situation;

2) Issue construction 1: Identifies alternative theoretical perspectives;

3) Issue construction 2: Identifies and elaborates on uncertainties;

4) Explanation and justification: Discusses effects on key stakeholders;

5) Conclusion: Clarifies values, synthesis and trade-offs.

For knowledge acquisition, the following five elements were used to assess the two team-projects, i.e., Team Showdown, and Team Showoff.

1) Develops a comprehensive understanding of the key concepts, theoretical frameworks and ideas of the issue of interest;

2) Takes into consideration the contextual and temporal properties of the information when providing an interpretation;

3) Recognizes patterns or configural effects or gestalt in making sense of the information;

4) Considers the influence of gaps in information, or the lack of information, or the presence of ambiguity in the information gathered;

5) Considers possible limitations and potential implications, and provides suggestions for future improvement.

To assess the degree to which students motivate themselves and others while participating in Talent Showcase and the various knowledge communities, the following criteria were used:

1) Motivating self-The Drive to Learn in Talent Showcase;

a) Acquire knowledge of an issue by searching for information from diverse sources;

b) Illustrate a comprehensive understanding of key concepts, frameworks and ideas related to the issue of interest.

2) Motivating others-Genuine Discourse in Online Knowledge Communities:

a) Encourage the community by sharing deep knowledge and enriching insights;

b) Pay close attention to the viewpoints of others and engage meaningfully in the community by providing well thought feedback and asking probing questions.

\section{Theoretical Justification for the Competency-Based Approach}

This section provides a brief account of the theoretical underpinnings of this competency-based pedagogical approach. Specifically, they are derived from the literatures on learner empowerment; epistemological belief systems; and, the so- 
cial construction of knowledge.

\subsection{Learner Empowerment}

Some students may see learning as an unpleasant burden or a necessary evil, at best. Not many perhaps will regard the task of learning as one of empowerment instead. Empowerment is a process that can generate intrinsic task motivation where the tasks assigned can enhance one's sense of self-efficacy (Frymier, Shulman, \& Houser, 1996).

Thomas and Velthouse (1990) identified four dimensions of such empowerment, viz., meaningfulness, competence, impact, and choice. They argued that meaningfulness denotes the value of a task in relation to one's beliefs, ideals, and standards. If the task to be done carries a lot of meaning for the doer, she will be motivated to do it well. Conversely, if an assigned task carried little meaning for the doer, then she will not be motivated to do it well.

The other three aspects are self-explanatory. Competence relates to one's confidence that derives from a sense of being qualified to and capable of doing an assigned task. Impact relates to the belief that one is making a difference, and thus is motivated to work hard as the performance of the task is important to one. Choice relates to one's freedom to decide task goals and the way to accomplish the task: the freer one is to decide, the more empowered one will feel.

Research verifies that empowered students learn better (Frymier, Shulman, \& Houser, 1996). The competency-based pedagogical approach attempts to empower learners by developing their cognitive competencies and interpersonal skills. Students become active learners when they are expected to apply cognitive thinking skills to critically examine a piece of information or to evaluate its ethicality based on several ethical approaches.

Such an active learning process can generate a sense of meaning and competence as students consciously work through their critical thinking and ethical reasoning processes to complete their course assignments. While the various assignments in the course described were designed with specific evaluation criteria in mind, the students were free to decide how they would complete those assignments, e.g., where to search for more information, how to organize the information in a meaningful way, and so on. By exercising such autonomy in completing their assignments, the students developed a sense of empowerment as active participants in knowledge acquisition.

\subsection{Epistemological Belief Systems}

The concept of epistemology has to do with the beliefs that people have about knowledge, specifically, what knowledge is and how knowledge is constructed. Such beliefs can have a significant impact upon the way we think and learn (Hofer, 2002; Bakx, VanDer Sanden, Sijtsma, Croon, \& Vermetten, 2006).

Hofer and Pintrich (1997) suggested that the nature of knowledge has two dimensions, i.e., the certainty of knowledge, and the simplicity of knowledge. They also argued that the nature of knowing likewise has two dimensions as 
well, i.e., the source of knowing, and the justification for knowing.

They found that: first, beliefs that regard knowledge as certain, i.e., believing in absolute and unchanging truths of a matter, is less sophisticated than those beliefs which regard knowledge as tentative and, perhaps, changing; secondly, beliefs that build on knowledge as something comprising knowable, discrete facts is less sophisticated than beliefs that build upon knowledge as something that is contingent and context-based; and, finally, beliefs that hold the sources of knowledge to be external authorities of some shape or form tend to be less sophisticated then beliefs that take knowledge to be understanding that emerges from and is constructed within interaction among interlocutors in communities of knowers.

Individuals tend to justify their beliefs based on how they evaluate the knowledge concerned using what evidence might be available and valid. Thus, it is important for educators to understand their students' epistemological belief systems so they can identify what teaching strategies might be ineffective (Marra \& Palmer, 2008). For example, students who do not see a certain body of knowledge, for example, sustainability, as important may store it as head knowledge that has absolutely no influence on their lives and behavior. When students perceive a certain body of knowledge as relevant and personally significant, they are more likely to internalize the learning and be more willing to put in the extra effort to examine what this might mean to them (Kuhn \& Weinstock, 2002).

Cognitive skills such as critical thinking and ethical reasoning compel learners to engage with problems, thereby evoking a sense of curiosity. That, in turn, can motivate true learning. Critical thinking is an essential skill for solving unstructured problems that have no ready solutions (Peach, Mukherjee, \& Hornyak, 2007). In working through a critical thinking rubric, students are compelled to examine the implications of their own beliefs and justify why they believe certain ideas. That is, instead of just being on the passive end of accepting information or content that their instructors may deliver, students learn to ask questions, challenge viewpoints of others, and seek additional information where it is needed.

Regarding the ways of measuring the knower in the process of acquiring knowledge, Glazer (1998) identified several critical elements. First, environmental and temporal contexts impart different meanings to different pieces of information, transforming some of them into knowledge that is relevant within a specific context. As such, the same piece of information may elicit different meanings in two different contexts or at two different points in time. Moreover, two different pieces of information may be associated with one under specific circumstances, resulting in what Glazer called "configural effects" or "gestalts" that help in pattern recognition, the skill of discerning which sets experts and novices apart, whatever the discipline.

The knowledge acquisition skill, which is critical to true learning, goes beyond the learning of specific content in a particular domain of knowledge. Instead, it involves the ability to question the clarity of theoretical concepts, their contex- 
tual relevance in real life situations, their relationships to other concepts, and any unstated assumptions. Students seldom ask probing questions that challenge the content of course materials. Instead of waiting for students to ask questions if and when they need clarification, it would be better to explicitly require students to generate questions instead. Generating questions require deep thinking. Thus, questioning well can promote deeper thinking for it is in the interstices between question and answer that minds are actively engaged.

Many a student may well assume that most questions have answers. Conversely, many an educator tends to ask students such questions to which she already has the answers. To promote deeper thinking, students should be encouraged to ask challenging questions that contain uncertainties or ambiguities for which there are no cut and dried answers. In this way, students might come to see that there is much more to find out. It is also a good idea to encourage students to ask difficult questions with no ready answers, which are inherently more interesting than those that can be answered.

For the Team Showdown project in the course mentioned, students were encouraged to ask questions at different levels of difficulty. In this way, students learned to not take the printed word at face value. Instead, they learned to grapple with the uncertainties inherent in the current state of knowledge about sustainability. In the process, they also developed the cognitive resilience to deal with the reality of incomplete information. This will conduce to a more sophisticated epistemological belief system.

Students who have to work through the various cognitive processes that might be involved in critical thinking, ethical reasoning, and knowledge acquisition, become more sophisticated in their epistemology in regard to the certitude of knowledge, the sources of knowing, and the justification for knowing.

\subsection{The Social Construction of Knowledge}

Famously, Berger and Luckmann (1966) eloquently made the case that reality is socially constructed by interlocutors engaging in symbolic interaction with one another. What is received as settled knowledge of that reality may be, in fact, simply that about which a social consensus exists. That is to say, knowledge is not something that one acquires as an atomistic individual, independent of others in our social world (Carley, 1986). Instead, knowledge acquisition is powered by social interaction. If so, what we know-or believe we know-is necessarily mediated by a multitude of social factors, including explicit and tacit individual and group assumptions, as well as individual and collective experiences, expectations, assumptions and biases.

In this construal, learning involves making sense of a reality as one participates in relevant communities of knowing. Even though thinking looks like the quintessential individual endeavor, in reality, as we make our views known to others and allowing them to assess and critique those ideas, we learn from one another. Meaning, then, is not something that is directly apprehended from some reading material, say. Instead, meaning must be activated and made rele- 
vant by communities of knowledge that facilitate the process of deliberation, argumentation, debate, and negotiation to navigate the tensions between received wisdom and emergent understandings.

In sum, knowledge is made relevant interpersonally within a community of co-knowers through a social process involving frequent and repeated interaction among members. In project teams, students learn about coordinating the different cognitive activities of members by observing for themselves how such a social process enables shared meanings and shared interpretive schemas to emerge. Such socially shared cognition, manifested as shared mental models, is then held individually as well as collectively among the members of a team (Patel et al., 1999; Patel et al., 2000).

\section{Evidence of Pedagogical Effectiveness}

Is there empirical evidence that this competency-based pedagogical course design was effective where it was adopted for the course mentioned, which was taught for three years in both the Fall and Spring semesters? No quantitative study was done but qualitative study of the end-of-course student evaluations over six consecutive semesters would suggest so. Table 1 provides some examples of the written feedback that students gave.

Table 1. Samples of qualitative feedback from students.

\begin{tabular}{|c|c|}
\hline Year/Semester & Samples of qualitative feedback from students \\
\hline 2012, Fall Sem. & $\begin{array}{l}\text { - Methods of teaching and recapping were creative. } \\
\text { - All the slides and lessons were uploaded at the start of the semester, showing } \\
\text { the extensive planning and preparation that was done beforehand. }\end{array}$ \\
\hline $\begin{array}{l}\text { 2012, Spring } \\
\text { Sem. }\end{array}$ & $\begin{array}{l}\text { - Lessons were always interesting and she did not spoon-feed us with answers, } \\
\text { but rather, kept us searching for more. } \\
\text { - Interesting and fun lessons. Concepts and importance of preserving the } \\
\text { environment presented in fun ways through presentations. Assignments } \\
\text { enabled me to delve deeper into the current environmental and sustainability } \\
\text { issues faced by companies. }\end{array}$ \\
\hline 2013, Fall Sem. & $\begin{array}{l}\text { - Interesting teaching style that focused more on student's peer learning. } \\
\text { - Through the course, I learnt a lot more on environmental sustainability and it } \\
\text { made me much more interested in this area of study. Overall, the different } \\
\text { activities also encouraged active participation. This is especially so for the } \\
\text { talent showcase, where "talent" of the week would engage in a discussion on } \\
\text { the week's topics. The class is not only informative, but also extremely } \\
\text { enjoyable! }\end{array}$ \\
\hline $\begin{array}{l}\text { 2013, Spring } \\
\text { Sem. }\end{array}$ & $\begin{array}{l}\text { - The class discussions and projects helped us analyze various companies and } \\
\text { their sustainability initiatives to assess if they were truly sustainable or not. } \\
\text { - A very well put together and engaging course that helped me develop my } \\
\text { understanding on key environmental issues and their implications for } \\
\text { business. }\end{array}$ \\
\hline 2014, Fall Sem. & $\begin{array}{l}\text { - Interesting lesson plan, made sure every student contributed and participated } \\
\text { in the seminars. Made the module more meaningful and useful for us. } \\
\text { - I came out of lessons feeling more "enlightened". }\end{array}$ \\
\hline $\begin{array}{l}\text { 2014, Spring } \\
\text { Sem. }\end{array}$ & $\begin{array}{l}\text { - Lessons were interesting as they were interactive and engaging. I learnt to be } \\
\text { more critical when analyzing issues. } \\
\text { - Used a wide variety of examples and videos related to the topics in business } \\
\text { sustainability. }\end{array}$ \\
\hline
\end{tabular}




\section{Instructor Pre-Course Preparation}

Students may find the flipped classroom with a competency-based pedagogical approach novel and, perhaps, intimidating. They will, therefore, need a lot of hand holding, so to speak. Lots of guidance and assurance will be needed to overcome their initial apprehension. Thus, it is of utmost important for the instructor to transform mindsets about learning and motivate a change in learning behavior from the very beginning of the course.

When the course mentioned was first adopted, it was necessary to put in a lot of effort to develop the teaching material needed to closely align learning outcomes, activities, and assessments. Pre-course preparation involved not only determining what content to include but also ensuring the availability of relevant and accurate information on the Internet. Some 13 sets of PowerPoint slides were prepared, which provided explanations about threshold theoretical concepts and frameworks for all topics covered in the course. In addition, an interactive e-book was also created that provided detailed information on the following matters:

1) Course design and context-providing the rationale for adopting the competency-based pedagogical design for the course; specifying the need to play the role of a "knowledge explorer" for learning; setting expectations on self-learning; and, establishing a "social contract" on collaborative learning in teams;

2) Course learning outcomes-providing detailed explanations on all assessment rubrics;

3) Course roadmap-providing details on the schedules for various learning activities;

4) Seminar guides_-providing clickable links to pre-selected YouTube videos and web-sites.

\section{Course Implementation}

All course materials were made available to students to download before the first class of the course. This reduced student anxiety levels about the course approach as they had ample time to become familiar with the course material and prepare for each class. In the flipped classroom setting, students were expected to go through the PowerPoints on their own to learn key concepts and frameworks. The instructor did not go through the PowerPoints in class. Instead, the student designated as "Talent of the Day" was expected to "showcase" their self-learning by applying key concepts and frameworks for a specific topic to explain the sustainability efforts of a business chosen specifically for discussion in class.

The entire course had a total of 13 seminar sessions. The first five seminar sessions were designed to provide students the opportunity to test run the various learning activities and become familiar with the criteria contained in various assessment rubrics. These trial runs helped students to become confident that they could perform despite the novel course design. The trial runs also enhanced their perception of their own self-efficacy in using the assessment rubrics as 
guides to complete the various assignments (Table 2 provides the scheduling of learning activities involved in a typical 3-hour seminar after the first five seminars).

\section{Discussion}

The learner-centered, flipped classroom as the fundamental way to reform instructional pedagogy in higher learning is gathering momentum (Butt, 2014). Not only does it enhance learning effectiveness but it is also a response to the existing educational system's impotence when it comes to equipping students with critical thinking and reasoning skills (Arum \& Roska, 2010).

In the course mentioned, the competency-based pedagogical approach was used to develop individual cognitive capabilities and interpersonal social skills that enabled better knowledge acquisition. The approach was deployed in a flipped classroom that focused on creating a learner-centered environment. To reform teaching pedagogy, course assignments were designed strategically as guided inquiries for students to explore the Internet to look for information on their own. The assignments also allowed them to practice their cognitive and social skills in making sense of such information.

Table 2. Scheduling of learning task for a typical three-hour seminar.

\begin{tabular}{|c|c|c|}
\hline Duration & Learning Activities & Main Objectives \\
\hline $\begin{array}{l}\text { About } 20 \\
\text { minutes }\end{array}$ & $\begin{array}{l}\text { Review \& Overview } \\
\text { 1) To conduct a quick review of the } \\
\text { previous class } \\
\text { 2) To provide a quick overview of the } \\
\text { current class }\end{array}$ & $\begin{array}{l}\text { To reinforce learning of threshold } \\
\text { theoretical concepts and frameworks }\end{array}$ \\
\hline $\begin{array}{l}\text { About } 40 \\
\text { minutes }\end{array}$ & $\begin{array}{l}\text { Talent Showcase } \\
\text { Pre-assigned students known as "Talent of } \\
\text { the Day" will discuss a chosen business case } \\
\text { study facilitated by the instructor }\end{array}$ & $\begin{array}{l}\text { To allow students to showcase their } \\
\text { self-learning of theoretical concepts } \\
\text { and frameworks by applying these to } \\
\text { the information gathered from the } \\
\text { Internet }\end{array}$ \\
\hline $\begin{array}{l}\text { About } 10 \\
\text { minutes }\end{array}$ & Mid-seminar Break & To rejuvenate and reenergize \\
\hline $\begin{array}{l}\text { About } 45 \\
\text { minutes }\end{array}$ & $\begin{array}{l}\text { Team Showdown } \\
\text { Showdown Team will guide other teams in } \\
\text { answering the questions generated by the } \\
\text { Team itself }\end{array}$ & $\begin{array}{l}\text { To facilitate collaborative knowledge } \\
\text { acquisition and sharing }\end{array}$ \\
\hline $\begin{array}{l}\text { About } 45 \\
\text { minutes }\end{array}$ & $\begin{array}{l}\text { Team Showoff } \\
\text { Showoff Team will present their findings } \\
\text { on the sustainability efforts of two business } \\
\text { corporations }\end{array}$ & $\begin{array}{l}\text { To facilitate collaborative knowledge } \\
\text { acquisition and sharing }\end{array}$ \\
\hline $\begin{array}{l}\text { About } 20 \\
\text { minutes }\end{array}$ & $\begin{array}{l}\text { Recapitulation } \\
\text { The instructor will provide a quick review } \\
\text { of the class }\end{array}$ & To reinforce learning \\
\hline $\begin{array}{l}24 \text { hours } \\
\text { after each } \\
\text { class }\end{array}$ & $\begin{array}{l}\text { Online Knowledge Communities } \\
\text { Students will motivate others to learn by } \\
\text { discussing issues of interest, voicing their } \\
\text { opinions, providing novel insights, or } \\
\text { asking probing questions }\end{array}$ & $\begin{array}{l}\text { To encourage genuine conversations } \\
\text { and engagement with others }\end{array}$ \\
\hline
\end{tabular}


Since getting good grades is an important motivation for student learning, the instructor must define the meaning of "good" in awarding grades for student performance. Genuine learning requires the active engagement of one's mind not only in understanding certain content but also in making judgments about what to believe and justifying one's beliefs, and viewpoints logically. In this context, a good grade is given to the student who develops the cognitive skills to critically examine information to assess if it is reliable and contextually appropriate, and ask what information is lacking or left out or ignored in the process of sense making (Davis et al., 1993).

For learning to take place, the learner must be motivated to learn. Motivated students engage course material in a meaningful way. It would be erroneous to assume that oral participation in class adequately indicates student engagement. Frymier \& Houser (2016) found but a weak relationship between engagement and oral participation. They identified three important aspects of engagement, viz., behavioral, emotional, and cognitive, all of which are invoked in this competency-based approach. All three aspects of engagement-behavioral, emotional, and cognitive-are interrelated and jointly impact the learning processes of students (Fredricks, Blumenfeld, \& Paris, 2004).

In the course mentioned, students were behaviorally, emotionally and cognitively engaged as they participated in meaningful deliberations among themselves. As they so deliberated, they were individually and collectively held responsible for critical thinking, ethical reasoning, and knowledge acquisition in dealing with ambiguities in sustainability. By assigning challenging team projects for which there were no ready answers to be found on the Internet, students were motivated to work collaboratively. Their emotions were also engaged as they actively critiqued the viewpoints of others or defended their own beliefs and ideas.

Moreover, this pedagogical approach encouraged genuine learning by raising student self-awareness about their prior personal epistemologies. By interrogating how credible a knowledge source might be, by questioning if the knowledge it provided was valid, and by participating in a social process of constructing a shared understanding within one's group, genuine conversations and meaningful debates were generated. Through exploring and uncovering hidden assumptions that underpinned their own beliefs or those of others, students were motivated to delve more deeply into a particular matter. Through a process of identifying information gaps and uncertainties, students became mindful of the limitations of the state of the art. As a result of this process of inquiry, students developed a heightened awareness of how many factors can influence one's knowing.

This competency-based pedagogical approach transforms thinking about course content and delivery. Instead of anguishing over whether content coverage is adequate in quantity and quality, with this approach, we begin by asking "What are the desired learning outcomes?" By looking forward to the end point and then reasoning backwards from that end point, the instructor can design her 
curriculum to equip her students with the competencies and skills to perform the tasks assigned and produce evidence of the learning that is expected. By making learning outcomes explicit and unpacking them clearly, students can clearly understand what is expected of them.

That unpacking of learning outcomes involves a process of developing reliable and valid assessment rubrics. Based on these assessment rubrics, one can design suitable learning activities as navigational tools to guide students to the desired learning outcomes. In designing quality learning activities, the following are needed, namely, 1) authenticity and relevance; 2) constructiveness and logical sequencing; 3) engagement of higher-order thinking; 4) alignment with learning outcomes; and, 5) motivation to learn (Meyers \& Nulty, 2009).

This competency approach also meets what Fink (2003) called the five principles of curriculum design, viz., encouraging higher level learning; promoting active learning; providing feedback on the quality of learning; applying a structured sequence to each learning activity; and, establishing a clear system for evaluating performance.

This approach advocates the delivery of course content using pedagogical methods to help students develop essential thinking competencies and interpersonal motivational skills; show students how knowledge is acquired and constructed; and, change the way they think about good learning outcomes. In brief, course content is delivered in such a way that students will be motivated to become active learners on their own accord.

The most difficult part about transforming the manner in which a course is taught is that the instructor must herself acquire new competencies and skills needed to create this new, dynamic learning environment for her students. To use the flipped-classroom, and technology-enabled learning strategies, the instructor will have to experiment with different techniques to assess their effectiveness in generating the desired outcomes. Of course, instructors are used to playing the role of the content expert who transmits determinate content. In that old world, only the reproduction of the instructor's knowledge is enabled rather than her thinking processes. In contrast, accessing content or domain knowledge may well be critical for learning, but it is only the first step in and not the end of learning. Instead, content is merely the fuel that powers the motivation for meaningful learning.

The change from passive learning to active learning will obviously challenge the student as well. Students are used to straightforward didactic teaching and comfortable with problems that have clear cut solutions. The competency approach, however, requires the student to navigate through a messy world of incomplete information shot through with ambiguities. In the real world, one frequently has to try to make sense of such information.

In order to implement this competency-based pedagogical approach successfully, there is then a need to establish a new set of expectations for students. It is important for them to understand what they need to do as active learners. To make the transition as smooth as possible, it is important to provide a compre- 
hensive course syllabus which explains the motivation for a flipped classroom with a competency-based course design. In addition, it should also contain guidelines on how to perform well in the course and highlight new expectations on self-regulated learning, collaborative work, and active engagement in class. For the course mentioned, an interactive e-book accessible online was designed to explain the rationale of the course design and set the expectations of how active learners were to be responsible for self-learning and collaborative learning. This e-book also contained detailed explanations on each assessment rubric used for grading student performance, which were the guidelines on how to perform well in said course. Finally, it also provided clickable links to the Internet as suggestions for information search.

\section{Conclusion}

This paper shows how a competency-based approach may be adopted in designing a flipped classroom to teach a sustainability course in an undergraduate program. The theoretical foundations that underpin the course design are discussed. They demonstrate how the three main components of said approach are tightly linked to one another, i.e., how specific learning outcomes are achieved through specially designed learning activities, and how these activities are evaluated using rubrics, which clearly define specific student behaviours that can be observed. These observable behaviours are the measure of the extent to which students achieve the specified learning outcomes.

Adopting this pedagogical approach could challenge both instructor and learner because it involves a wholesale re-examination of the meanings of teaching and learning and, pari passu, of instructor and learner. In order for both parties to benefit from the approach, a paradigm shift in one's mental model of teaching and learning is called for. That is, the giver-and-receiver model is put away in favour of a fellow-explorer model that emphasizes out-of-class selfregulated learning, peer-assisted learning, and team-based collaborative learning. Content knowledge and insights thus garnered are actively shared by students within the flipped classroom itself, where the instructor plays the role of coach, offering guidance, motivating discussion, and gives timely feedback, when appropriate. This model calls for a lot more work on the part of both student and instructor but the active learning it engenders makes it worth the while.

\section{References}

Alghalith, N. (2015). Using Course-Embedded Assessment: Defining and Assessing Critical Thinking Skills of MIS Students. Journal of Higher Education Theory and Practice, 15, 77-83.

Arum, R., \& Roska, J. (2010). Academically Adrift: Limited Learning on College Campuses. Chicago, IL: University of Chicago Press. https://doi.org/10.7208/chicago/9780226028576.001.0001

Bakx, A. A., VanDer Sanden, J. M., Sijtsma, K. K., Croon, M. A., \& Vermetten, Y. M. (2006). The Role of Students' Personality Characteristics, Self-Perceived Competence and Learning Conceptions in the Acquisition and Development of Social Communica- 
tive Competence: A Longitudinal Study. Higher Education, 51, 71-104.

https://doi.org/10.1007/s10734-004-6377-6

Berger, P. L., \& Luckmann, T. (1966). The Social Construction of Reality. Garden City, NY: Anchor Books.

Butt, A. (2014). Student Views on the Use of Flipped Classroom Approach: Evidence from Australia. Business Education \& Accreditation, 6, 33-43.

Carley, K. (1986). Knowledge Acquisition as a Social Phenomenon. Instructional Science, 14, 381-438. https://doi.org/10.1007/BF00051829

Davis, R., Shrobe, H., \& Szolovits, P. (1993). What Is a Knowledge Representation (pp. 17-33)? AI Magazine, Berlin: Springer.

Driscoll, A., \& Wood, S. (2007). Developing Outcomes-Based Assessment for LearnerCentered Education: A Faculty Introduction. Sterling, VA: Stylus.

Ewell, P. (2001). Accreditation and Student Learning Outcomes: A Proposed Point of Departure. Washington DC: Council for Higher Education Accreditation.

Fink, L. D. (2003). Creating Significant Learning Experiences. San Francisco, CA: JosseyBass.

Fredricks, J. A., Blumenfeld, P. C., \& Paris, A. H. (2004). School Engagement: Potential of the Concept, State of the Evidence. Review of Educational Research, 74, 59-109. https://doi.org/10.3102/00346543074001059

Frymier, A. B., Shulman, G. M., \& Houser, M. (1996). The Development of a Learner Empowerment Measure. Communication Education, 45, 181-199.

https://doi.org/10.1080/03634529609379048

Frymier, A. B., \& Houser, M. L. (2016). The Role of Oral Participation in Student Engagement. Communication Education, 65, 83-104. https://doi.org/10.1080/03634523.2015.1066019

Glazer, R. (1998). Measuring the Knower: Towards a Theory of Knowledge Equity. California Management Review, 40, 175-194. https://doi.org/10.2307/41165949

Hofer, B. (2002). Personal Epistemology as a Psychological and Educational Construct. In B. Hofer, \& P. Pintrich (Eds.), Personal Epistemology (pp. 3-14). Mahwah, NJ: Lawrence Erlbaum.

Hofer, B. K., \& Pintrich, P. R. (1997). The Development of Epistemological Theories: Beliefs about Knowledge and Knowing and their Relation to Learning. Review of Educational Research, 67, 88-140. https://doi.org/10.3102/00346543067001088

Kuhn, D., \& Weinstock, M. (2002). What Is Epistemological Thinking and Why Does It Matter? In B. Hofer, \& P. Pintrich (Eds.), Personal Epistemology: The Psychology of Beliefs about Knowledge and Knowing (pp. 121-144). New York, NY: Routledge.

Marra, R. M., \& Palmer, B. (2008). Epistemologies of the Sciences, Humanities, and Social Sciences: Liberal Arts Students' Perceptions. JGE: The Journal of General Education, 57, 100-118. https://doi.org/10.1353/jge.0.0017

Meyers, N. M., \& Nulty, D. D. (2009). How to Use (Five) Curriculum Design Principles to Align Authentic Learning Environments, Assessment, Students' Approaches to Thinking and Learning Outcomes. Assessment \& Evaluation in Higher Education, 34, 565577. https://doi.org/10.1080/02602930802226502

Patel, V. L., Cytryn, K. N., Shortliffe, E. H., \& Safran, C. (2000). The Collaborative Health Care Team: The Role of Individual and Group Expertise. Teaching and Learning in Medicine, 12, 117-132. https://doi.org/10.1207/S15328015TLM1203_2

Patel, V. L., Kaufman, D. R., Allen, V. G., Shortliffe, E. H., Cimino, J. J., \& Greenes, R. A. (1999). Toward a Framework for Computer-Mediated Collaborative Design in Medical 
Informatics. Methods of Information in Medicine, 38, 158-176.

Peach, B., Mukherjee, A., \& Hornyak, M. (2007). Assessing Critical Thinking: A College's Journey and Lessons Learned. The Journal of Education for Business, 82, 313-320. https://doi.org/10.3200/JOEB.82.6.313-320

Rusinko, C. A., \& Sama, L. M. (2009). Greening and Sustainability across the Management Curriculum: An Extended Journey. Journal of Management Education, 33, 271275. https://doi.org/10.1177/1052562908327639

Thomas, K., \& Velthouse, B. (1990). Cognitive Elements of Empowerment: An "Interpretive" Mode of Intrinsic Task Motivation. Academy of Management Review, 15, 666681.

Submit or recommend next manuscript to SCIRP and we will provide best service for you:

Accepting pre-submission inquiries through Email, Facebook, LinkedIn, Twitter, etc. A wide selection of journals (inclusive of 9 subjects, more than 200 journals)

Providing 24-hour high-quality service

User-friendly online submission system

Fair and swift peer-review system

Efficient typesetting and proofreading procedure

Display of the result of downloads and visits, as well as the number of cited articles Maximum dissemination of your research work

Submit your manuscript at: http://papersubmission.scirp.org/

Or contact ce@scirp.org 